\title{
Expert system for new product strategy development
}

\author{
Marimin ${ }^{\dagger} \ddagger$, Lien Herlina ${ }^{\ddagger}$, Andri Aulia ${ }^{\S}$, Motohide Umano*, Itsuo Hatono ${ }^{\dagger}$, and \\ Hiroyuki Tamura ${ }^{\dagger}$ \\ ${ }^{\dagger}$ Department of Systems and Human Science \\ Graduate School of Engineering Science, Osaka University \\ 1-3 Machikaneyama, Toyonaka, Osaka 560, Japan \\ E-mail: tamura@sys.es.osaka-u.ac.jp \\ $\ddagger$ Department of Agro-Industrial Technology \\ Faculty of Agricultural Technology, Bogor Agricultural University \\ P.O. Box. 220, Bogor 16002, Indonesia \\ E-mail: ftetaipb@server.indo.net.id \\ $\S$ Good Year, Co., Bogor, Indonesia \\ *Department of Mathematics and Information Sciences \\ College of Integrated Arts and Sciences, Osaka Prefecture University \\ 1-1 Gakuen-cho, Sakai, Osaka 593, Japan \\ E-mail:umano@mathsun.cias.osakafu-u.ac.jp
}

\begin{abstract}
This article discusses key issues in designing and implementing an expert system for new product strategy development. The expert system prototype is able to create a product development strategy plan that guides product development efforts of companies, i.e., soap industries which matches with market, consumers needs and firm's ability and potencies comprehensively. One of its outputs is a guideline to product developers about the critical factors and focuses of the products. It also provides as a tool for involving consumers in the product development processes. The system is implemented by using an expert system shell on a PC environment.
\end{abstract}

\section{Keywords}

Product development strategy, heuristic approach, soap industry, systematic knowledge acquisition, frame-tree knowledge representation

\section{INTRODUCTION}

New product strategy is a master plan that guides product innovation efforts of the company, and links new product development to the corporate plan. It is considered as a key factor for maintaining or even developing progress of companies. Complex internal and external factors that include consumers' requirements must be considered to develop the strategy (Cooper, 1987; Ciccantelli and Magidson, 1995). It is a semi- or fully-unstructured problem which deals with uncertainty internal to the firm as well as external to the firm such as technology, politics and organizational priorities (Barczak and Wilemon, 1991). A suitable method must be used to handle these uncertainties. 
Some methods have been used for new product strategy development which usually consist of creative thinking and brain storming stages. They are supported by suitable communication and leadership patterns within the product developer team and also between the team and the related divisions in the company. Some success product development processes are, e.g., a "Product launch model", and a "Gating System" (Bart, 1995). These methods rely on coordination and sequential phases. However, the new direction for the product development relies on the integration and overlapping activities (Allen et al., 1995). Moreover, creating product development strategy suitable for a specific company is a time- and cost-consuming process.

As one alternative to solving the problem, we propose an expert system for new product strategy development (ESPROSD). The expert system prototype is able to guide product developers identify the critical factors and focuses of the product that include the main physical characteristics, the benefits of the main factors, packaging design and marketing guidance for the new product strategy development. It also provides as a tool for involving consumers in the product development processes.

\section{DEVELOPMENT METHODOLOGY}

This research identifies the critical factors analysis and direction of the product development strategy that can be assisted by an expert system. It accommodates qualitative and quantitative factors, and certain and uncertain values through a heuristic process.

The method used for developing the expert system is similar to that suggested by Marimin et al. (1995). It consists of several steps: problem identification and selection, experts selection and knowledge acquisition, knowledge representation, reasoning model development, software selection and implementation, validation, verification and testing.

The product development stages followed by the knowledge engineer $(\mathrm{KE})$ as the basic for the knowledge acquisition process are those suggested by Ciccantelli and Magidson (1995). The main stages are (1) brain storming and/or consumer design session to identify and to define the product concept, focus group and survey in target markets to develop physical design and manufacture prototype, (2) product idea modification based on focus groups and survey, (3) market test prototype, (4) revision, and (5) finish product or service goes to market test.

Knowledge is collected from the related experts, practitioners and published materials through systematic knowledge acquisition. Rules are designed to represent relations among parameters. Certainty factor is used to resolve uncertain information. The rules, parameters and variables are packed into a frame-tree knowledge representation. Conclusions are inferred through forward and backward reasoning using a tree search with the pruning control strategy. The system is applied to a soap industries product development case using a Personal consultant plus expert system shell on a PC environment.

The expert system prototype is tested internally to ensure that it implements the system correctly. Its performance is also tested externally by the experts contributed in the system development and the potential users (product developer practitioners). The validation checklist, guideline, and procedure used are those suggested by Meseguer (1993). The technical operation validation steps followed are those suggested by Texas Instrument (1986). 


\section{KNOWLEDGE ACQUISITION}

\subsection{The Critical Factors Consideration}

Many factors must be considered to create a new robust product. Some common internal critical factors include but are not limited to (1) product factors: product complexity, product innovation, and design maturity at validation turnover; (2) process factors: schedule pressure, validation intensity, corrective action aggressiveness, and corporate commitment to the program (Zurn, 1991). Many other factors may exist specific to each company and its product lines. For example in the soap industry the factors include health benefits and environment impact especially a water pollution aspect. The external factors include targeted consumers' preference, attitude and culture, consumers needs, competitors, product regulations, and the related business environment. These factors can be ranked according to their degrees of criticality.

The key success factors in the product development then in marketing are usually include: product quality, product development: price, know-how, product reliability, service, flexibility and after-sales service, customer requirements, technology, and internationalization: promotion and marketing. Those can be classified into several issues namely; product features, technical, customer needs, marketing, manufacturing, schedule, financial, managerial and resources issues in which customer needs are the most important (Barczak and Wilemon, 1991).

The critical factors can be obtained from several sources: users or customers, market organizations, fairs, research institutes or universities, journals, books, and other research reports and information media, competitors, international patent publications and others.

The factors collected should cover the main factors affecting to all product development stages. Although the product development stages are different on each expert, the basic stages are similar. They include ideas development, concept development, concept pre-test, prototype development, prototype market test, modification and refinements. A care must be taken in every stage to ensure that the result of that stage is free of flaws. Before the newly introduced product goes to mass production, it must be comprehensively re-tested in various stages of its product development cycle (Ciccantelli and Magidson, 1995). The test should also focus on the coverage of the product to the customer requirements.

\subsection{The Acquisition Process}

We select a soap industries product development as a case for the expert system prototype testing. Sources of expertise used to develop the expert system are an expert from a product development consulting company, two experts from product developer managers, one expert from a university, and available written materials such as journals, books, and research reports.

The knowledge acquisition methods used are a combination of discussion, problem description, and guided interview. KE met with each expert at least twice. In the first time, KE outlined the problems to be solved, went through some details and sometimes verified the knowledge already collected. Through an interactive process, 
it is possible to obtain clear systematic decision paths and their associate parameters and variables of the new product strategy development.

An example of the knowledge acquisition process is shown in Table 1. The acquisition process starts from general subject matters; the reasons of the problem existence and complexion, and the suitable method to solve the problem. Then the process goes into some detail factors, variables and parameters associated to the problem.

Table 1 Knowledge acquisition process.

\begin{tabular}{ll}
\hline KE & Knowledge Acquisition \\
Expert & $\begin{array}{l}\text { What are the main purposes of a product strategy development } \\
\text { for a company? } \\
\text { Product development can be classified into a new product, a } \\
\text { new brand, and new service development. The main purpose of } \\
\text { these product strategies is for maintaining and/or } \\
\text { developing the progress of the company. }\end{array}$ \\
KE & $\begin{array}{l}\text { What are the main factors for developing the strategy? } \\
\text { Expert }\end{array}$ \\
& $\begin{array}{l}\text { There are various factors which include internal and external } \\
\text { factors. The internal factors are, e.g., product } \\
\text { characteristics, product life cycle, and the global corporate } \\
\text { plan of the company. The internal factors are, e.g., product } \\
\text { competitors, product position and market share of the targeted } \\
\text { consumers' level, attitudes, culture value, and regulations of } \\
\text { the governing body. } \\
\text { (Asks for details about the factors.) } \\
\text { (Provides details.) }\end{array}$ \\
KE & The discussion continues ...
\end{tabular}

The knowledge collected is then classified into static and dynamic types. The static knowledge is represented in the form of frames and parameter values, while the dynamic knowledge is represented using production rules which represent relations among parameters that can be used to infer conclusions.

The parameters are classified into two types; ordinary and intermediate parameters. The ordinary parameter values are set directly by KE during system design, or are provided by user during consultation. The intermediate parameter values are computed during reasoning process using the appropriate rules.

The ordinary parameters include, but are not limited to, competitor, market, distribution, product-user, product-buyer, promotion type and budget, price, economicsituation, customer loyalty, customer-preference, product-characteristic and packaging design and type. The intermediate parameters include, but are not limited to, market type, environment type, product position, and requirement level. The logical structure of the main parameters are shown on Figure 1. It is used as the basic decision path in the reasoning process. It shows that there are 5 levels of parameters in which New-product-strategy is the highest (the goal parameter), while the others are either intermediate parameters or the subgoal parameters (e.g., Market-trend, En- 
vironment, etc.) or ordinary parameters (e.g., Types of buyers, Promotion, Potency, etc.).

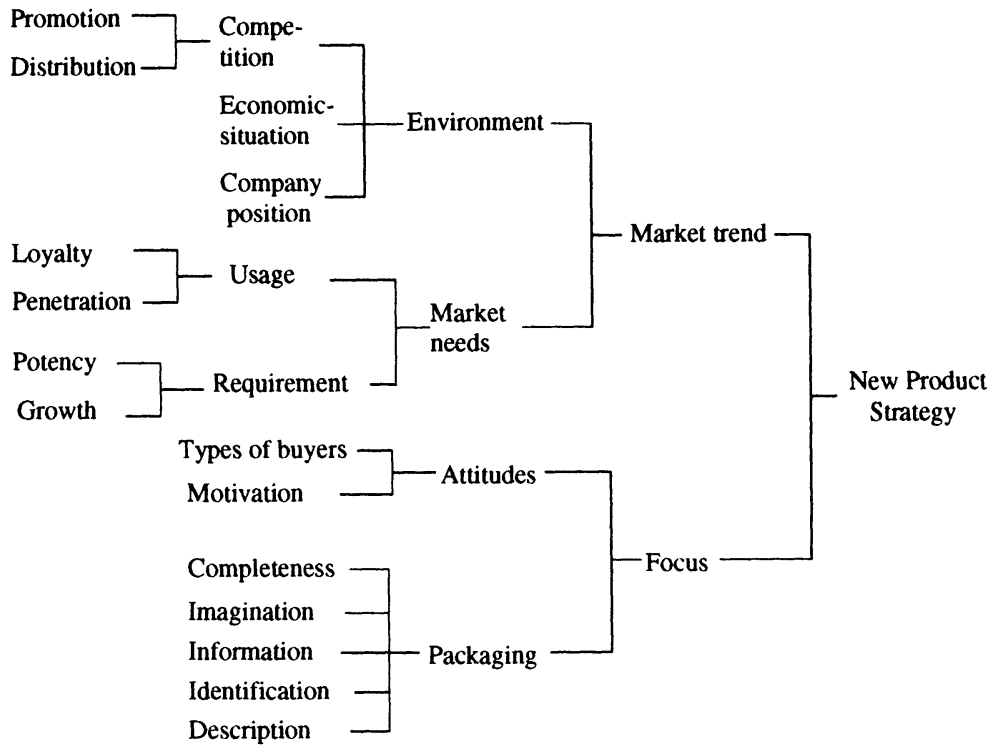

Figure 1 The logical structure of the main parameters.

Part of the knowledge consists of uncertain information. This uncertainty is handled by using a certainty-factor technique (Shortliffe, 1976). After the first discussion with experts, KE classifies the parameters as exact or inexact. The inexact parameters are provided with initial certainty-factor $(c f)$ values. These values are discussed with the experts to get the final basic $c f$ values both in parameters and in the associated rules.

\section{DESIGNING THE SYSTEM}

\subsection{The Knowledge Representation}

The knowledge is packed into a frame tree that its structure is shown in Figure 2. The frame tree consists of a root frame (Product-Development), a subframe 1 (ProductCharacter), and a subframe 2 (Marketing). Every frame consists of frame properties, a parameter group, and a rule group.

Root-frame properties include goals, initial data, and translation describing the purpose of the frame. The subframe properties include goals (optional), initial data, translation, and occurrence. The goal property is a list of one or more parameters that conclude the frame. The occurrence value is used to specify the number of times of the frame can be instantiated.

The parameter group represents all parameter names used. Each parameter has properties which represent the kinds of expected values, and the prompt that asks 


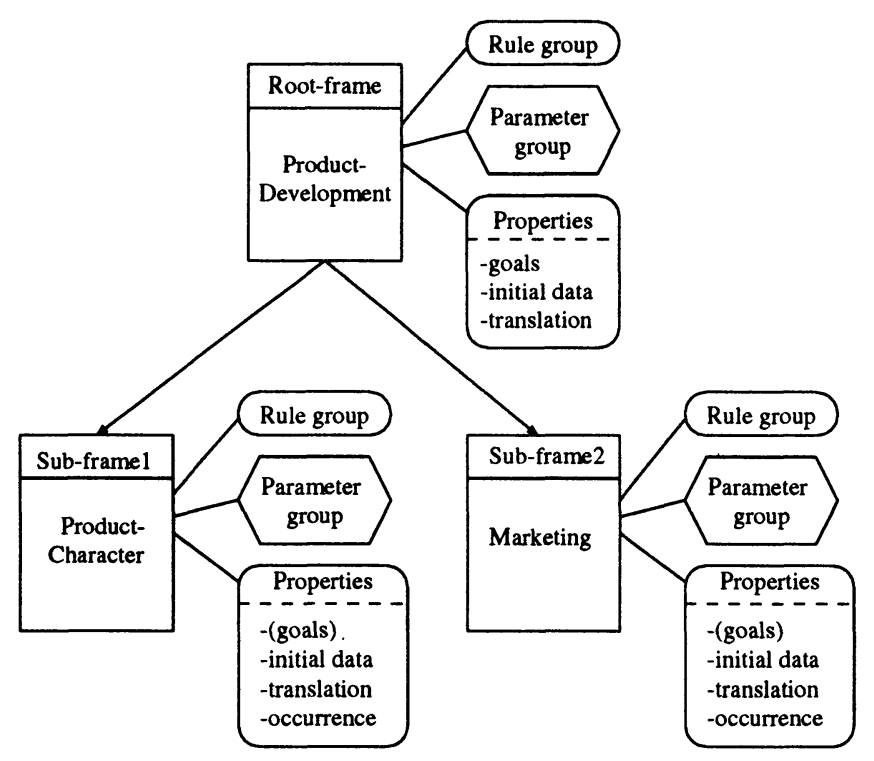

Figure 2 A Tree frame structure.

the user for the parameter value. The parameter properties include type of parameter, translation, prompt, help, and expected legal-values. The parameter types used are ask-all, multi-valued, single-valued, yes/no, and textag which represents a piece of text. These parameter types are useful for gathering information from the user during consultation.

Rules are used to specify how to infer a parameter's value from the current consultation, to show the logical relationship between parameters, to communicate information to the user, and to infer conclusion from the facts available. Every rule has structure and information properties. The rule structure properties consist of antecedent, explanation, if, invalid, and then properties. The rule information properties consist of optional user-defined properties such as comment, and the time of the rule is created.

The antecedent property specify the way the rule is being used, either consequent (when its value is NO) or antecedent (when its value is YES). The explanation property will enable the system to justify a conclusion. The IF property value is "if" part of an if-then rule. The INVALID property is used to indicate whether the rule is correctly edited to the system. The THEN property is the "then" part of an if-then rule.

Rule 20 is an example of an antecedent rule.

Rule 20:

IF(Buyer=Benefit) AND

(Motivation=Emotional)

THEN Attitude $=$ Attitude 1

EXPLANATION: Attitude 1 is a type of customer preference and behavior toward the product.

ANTECEDENT : YES

(INVALID : NO) 
In the example above, Buyer, Motivation and Attitude are parameters. Benefit and Emotional are values which are supplied by the user. Attitude is an intermediate parameter which is being used by other rules to derive the final conclusion.

The parameter values of some rules are provided with a $c f$ value. Rule 85 is an example of a consequent rule with a $c f$ value on its parameter value.

Rule 85:

IF(Promotion=Consumer-belief)

THEN Competition=Tight $(\mathrm{cf}=0.80)$

EXPLANATION: The final competition level

will be computed by the other

associated rules.

\section{(ANTECEDENT : NO)}

By considering the $c f$ value, one can suggest that a conclusion or a situation did not occur, very likely did not occur, probably dit not occur, is doubtful, probably occurred, very likely occurred, or did occur (Marimin et al., 1995).

\subsection{The Reasoning Mechanism}

Exact and inexact reasoning are used to infer conclusions from knowledge stored in the knowledge base and some other information provided by user during consultation process. The process results a set of conclusions with certainty factors information on some of its elements.

Rules are processed depending on their types: consequence rules, antecedent rules, or self-referencing rules. About 75 percent of the rules implemented are consequent rules.

The consequent rules are the coded hypotheses form that can be tested to prove the conclusion. The system first determines the goal parameter(s) that constitute(s) the conclusion, and then test the associated hypotheses or rules. The search method used is backward-chaining which focuses on finding rules to provide necessary parameter values. When the system needs a parameter value, it searches a rule that might set the value of that parameter. If it is found, the system tests the IF statement of that rule to see that value. If it is successful, then the THEN statement of the rule is performed, otherwise the system searches other rules to conclude the unknown parameter value. If there are no rules left, the system asks the user to provide a value of that parameter.

The system uses antecedent rules when the value of one parameter implies the other value. This can keep the system from asking too many or redundant questions. Let us consider Rule 20 of the previous section. The system allows the user to provide Buyer and Motivation parameter values. When the values are provided, the system directly deduces that the Attitude is Attitude 1 which has already defined in the knowledge base. The Attitude 1 value is not necessarily asked of the user. The rules are tried when one of their premise parameters has been traced during consultation. When they are tried, they do not force tracing of their premise parameters, but they rely on known information within the system. The antecedent rules use forward chaining search to find other rules that derive new facts or values for their parameters.

A self-referencing rule refers a parameter in the IF statement and then concludes a value for the same parameter in the THEN statement. This rule can be either consequent or antecedent rule. It is very useful for assigning a default value to a parameter 
if all other applicable rules have failed, and to modify certainty factor value of a parameter based on other conditions in the IF statement.

Intermediate and final $c f$ values of the suggested conclusions resulting from several decision paths are computed in the following steps. The certainty factor of the IF statement is calculated; when the statement is combined with an AND function, each of its clause must be true for the IF statement to be true. Its certainty factor is the minimum certainty factor of the clauses. When the statement is combined with an $\mathrm{OR}$ function, the statement is true if there is at least one clause is true. Its certainty factor is the maximum certainty factor of the true clauses.

In the system implementation, in order the THEN statement to be executed (i.e., for a rule to pass), IF statement must be tested true with a certainty factor at least 0.2 . When the parameter value being concluded has a previous $c f$ value associated with it, the new $c f$ value is computed according to the $c f$ value on the IF statement and the cf value on the THEN statement.

Knowledge about the particular problem is useful to guide the chaining process. It includes deciding which subproblem space to disregard or discard. This idea is called tree search with pruning control strategy. It is used as a part of the reasoning process. An example of such a process is shown in Figure 3.

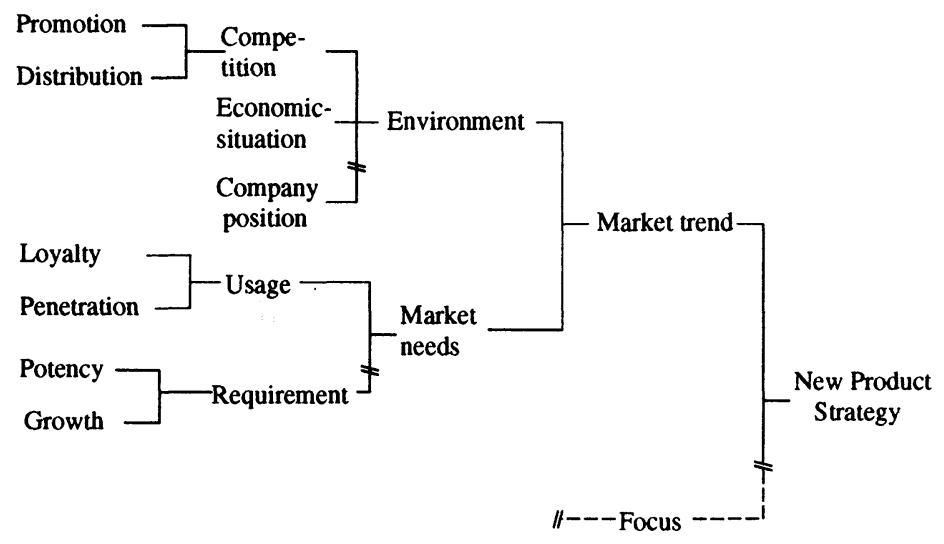

Figure 3 Tree search with pruning control strategy.

Suppose, in a consultation, user provides value customer-belief to parameter Promotion and YES to parameter Distribution, then the system traces the value of Competition parameter. Based on an available rule, the Position should be Competition 1. Then the system traces the Environment parameter value. In that case, there is no rule that directly deduces Competition 1 into the Environment value. However, there is a rule that deduces Competition 1 and an Economic-situation parameter value into an Environment value. The system asks the user to provide an Economic-situation value. When it is provided, the Environment value is deduced, and a path leading to the Company Position is cut. This process continues a long the paths leading to the goal parameter, i.e., until it suggests the intended conclusion, a set of new product strategy. The search methods used to find the rules are forward and backward 
depending on current position of the parameter and its associated rule type being tested.

\section{VERIFICATION AND DISCUSSION}

During the consultation process, the user provides static and dynamic inputs to the system. Some hidden information is not necessarily asked of the user, since such information is either common in nature or too technical to be shown to a regular user. In this case, the $\mathrm{KE}$ puts such knowledge in a static hidden knowledge base together with the associated models or rules. Some basic information for dynamic inputs should be collected from market and product researches. If such information is not available, default values provided by the system can be used.

The static inputs include a product position in its life cycle, economic situation, and product distribution area. These static input choices can be updated by the $\mathrm{KE}$ or a programmer based on new knowledge collected from marketing and product researches. The dynamic inputs include cost, usage, attitudes (targeted consumer behavior and preferences), and competitors.

Each input parameter has its own type, either ask-all, yes/no, multi-valued or single-valued in which some of the parameters are provided with certainty factor values. The user interface of the system is designed in such manner that the user can easily interact with the system. The user may update, cancel, ask on-line help, or ask a justification to certain conclusion. The consultation log together with the output can be directed into several output formats.

An example of summarized user inputs to questions asked by the system during a consultation set is shown in Table 2. Some of the questions asked are market growth, product usage, competitors and economic situation, company position in the competition, product position, and customer preference and attitudes toward the product and its packaging design. The system will generate a suitable user interface for each parameter asked. Figure 4 is an example of such a user interface. In that case, competitor is a single-valued parameter. The user selects one of the provided options and set the associated $c f$ value (i.e., one point represents $10 \% c f$ value).

The system processes the inputs interactively through reasoning strategies which have been designed. The outputs are suggestions toward the product developers in the critical factors and focuses of the product that include the main physical characteristics, the benefits of the main factors, packaging design and marketing guidance for the new product strategy development.

The outputs are incorporated with $c f$ values, and the user gives priority to the suggestions accordingly. Table 3 is a summary of a set of consultation outputs based on inputs listed on Table 2.

Table 3 shows that the focus of the product should be in the physical characteristics (texture and smoothness), health benefit, and packaging comportability. The system also suggests for introducing completely a new product or the same product but with different type of appearance and packaging.

For validation and verification purposes, the expert system prototype was tested and judge by the experts who are participated in the development process. Based on their suggestions, the system is revised on several areas, especially the user interface, the help facility, and the static parameter values. The revised system prototype was 
Table 2 Summarized inputs on a set of consultation.

\begin{tabular}{ll}
\hline Parameters & Values \\
\hline - Product's user type & New-comers \\
- Number of competitors & A few: 60\% \\
- Sales condition & Increase: 70\% \\
- Consumers' cost consideration & YES \\
- Marketing cost consideration & YES \\
- Economic situation & Stable: 60\% \\
- Company position in the com.. & Market-leader \\
- Approach of the product sale & Consumer-belief \\
- Usage of competitor distri.. & YES \\
- Product penetration at mar.. & High: 60\% \\
- Consumers loyalty & High: 60\% \\
- Market potency & Wide \\
- Consumer acceptance analysis & YES \\
- Main factor consumer to buy .. & Benefit \\
- Consumer motivation to buy .. & Emotional \\
- Packaging distinctivity & YES \\
- Product liability & YES \\
- Consumer awareness & NO \\
- Direction on the packaging & NO \\
\hline
\end{tabular}

Table 3 Summarized outputs of a consultation process with inputs listed on Table 2.

Conclusion for Frame Product

Focus of the product development:

- Subjective physical characteristics: e.g., texture and smoothness

- Health benefits: e.g., cleaning strength

- Packaging design: e.g., consumers' comportability

Conclusion for Frame Marketing:

- Please focus on the consumers requirements

- Market is still high, therefore please introduce new models or appearance of the product $(60 \%)$.

Special attentions:

- Physical subjective characteristics 
How is the number of competitors trend?

(Press F1 for clarification)

YES

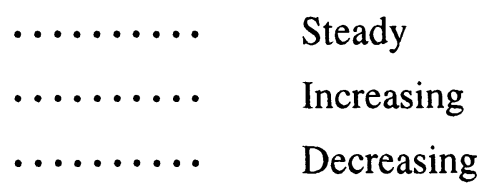

1. Use arrow key to indicate your degree of certainty

2. To select one item, with $100 \%$ certainty, press CRTL-right arrow

3. After making selection, press ENTER to continue

Figure 4 An example of a user interface for obtaining a parameter value from the user.

accepted by the experts as a system that could assist rather than substitute them in developing a new product strategy. The system was also tested by regular users, the product developer practitioners. According to them, the system could assist them especially in the initial stages of the new product strategy development. It should be expanded to wider aspects of the development such as in the product prototype design.

\section{CONCLUDING REMARKS}

The expert system for new product strategy development can be used to assist soap industry companies and/or product development consulting companies in creating product development strategy especially in the initial stages of the product development processes. It also provides as a tool for involving consumers in the development process.

Further work is needed to fully implement the system comprehensively, such as in the new product prototype design. By doing so, it will enable the system creates a more complete new product strategy.

The expert system prototype can be applied to similar industries with different products or locations through some parameter modifications.

\section{REFERENCES}

Allen, T.J., C. Karlsson, and F. Norrgren. (1995). Introduction to the cluster of product development. IEEE Tran. Eng. Management, 42(2), pp. 191.

Barczak, G. and D. Wilemon. (1991). Communications patterns of new product development team leaders. IEEE Tran. Eng. Management, 38(2), pp. 101-109.

Bart, C.K. (1995). Gagging on Chaos. IEEE Tran. Eng. Management Rev., 23(2), pp. 41-49. 
Ciccantelli, S. and J. Magidson. (1995). Involving consumers in the product development process. IEEE Tran. Eng. Management Rev., 23(1), pp. 30-34.

Cooper, R.G. (1987). Defining the new product strategy. IEEE Tran. Eng. Management, em-34(3), pp. 184-193.

Marimin, Eriyatno, S.A. Muktirizka, and H. Tamura. (1995). Expert system for product-advertising-strategy development. J. Intell. and Fuzzy Systems, 3(2), pp. $107-116$.

Meseguer, P. (1993). Expert system validation through knowledge base refinement. Proc. $13^{\text {th }}$ Int. Conf. Artif. Intell. Chambery, France, pp. 477-482.

Shortliffe, E.H. (1976). Computer-based medical consultation: MYCIN. Elsevier Science, New York.

Texas Instrument. (1986). Personal Consultant Plus (PC-plus) Technical User Manual. Austin, TX.

Zurn, T. (1991). Problem discovery function: A useful tool for assessing new product introduction. IEEE Tran. Engineering Management, 38(2), pp. 100-119.

\section{BIOGRAPHY}

Dr. Marimin is a lecturer at Department of Agro-industrial Technology, Bogor Agricultural University, Indonesia. He received a Ph.D. degree from Department of Systems and Human Science, Graduate School of Engineering Science, Osaka University, Japan. The title of his dissertation is "Linguistic labels based methodology for fuzzy group decision making". His research interests include fuzzy expert systems, fuzzy group decision making, and their applications to product development and management technology.

Mrs. Lien Herlina is a lecturer at Department of Agro-industrial Technology, Bogor Agricultural University, Indonesia. Her research interests include product development and marketing.

Mr. Andri Aulia is a production staff at Good Year Co, Bogor, Indonesia. His research interests include applications of expert system on new product development.

Dr. Motohide Umano is a professor at Department of of Mathematics and Information Sciences, College of Integrated Art and Sciences, Osaka Prefecture University, Japan. His research interests include fuzzy-set oriented programming languages, fuzzy databases, fuzzy expert systems and fuzzy knowledge information processing.

Dr. Itsuo Hatono is an assistant professor at Department of Systems and Human Science, Graduate School of Engineering Science, Osaka University, Japan. His research interests include production scheduling for complex and large production systems, and modeling of discrete event systems such as manufacturing systems and computer networks.

Dr. Hiroyuki Tamura is a professor at Department of Systems and Human Science, Graduate School of Engineering Science, Osaka University, Japan. His research interests center on the systems methodology for large-scale systems such as modeling, control and decision making, and their applications to manufacturing systems and public systems. 